\title{
The conservation status assessment of Natura 2000 forest habitats in Europe: capabilities, potentials and challenges of national forest inventories data
}

\author{
Iciar Alberdi ${ }^{1}$ (D) - Leónia Nunes ${ }^{2,3} \cdot$ Marko Kovac $^{4} \cdot$ Ingrid Bonheme $^{5} \cdot$ Isabel Cañellas ${ }^{1} \cdot$ Francisco Castro Rego $^{2}$. \\ Susana Dias ${ }^{2} \cdot$ Inês Duarte ${ }^{2} \cdot$ Monica Notarangelo $^{6} \cdot$ Maria Rizzo $^{6} \cdot$ Patrizia Gasparini $^{6}$
}

Received: 31 January 2018 / Accepted: 7 March 2019 / Published online: 3 April 2019

(C) The Author(s) 2019

\begin{abstract}
- Key message There is a need to improve the consistency of international information concerning the conservation status assessment of the species and habitat types in the Natura 2000 reports. National Forest Inventories could contribute towards a more objective and harmonised assessment although their use shows some challenges as low precision for rare or small area habitats. Recommendations for a set of 12 structural and functional indicators are provided.

- Context There are differences among Member States as regards applying conservation status assessment and priorities according to the Directive on the conservation of natural habitats (Habitats Directive).

- Aims This paper aims to analyse the consistency as regards forest habitat types reporting and the use and suitability of National Forest Inventories (NFIs) to assess their conservation status, as well as to provide recommendations for harmonised assessments through NFIs. - Methods A survey was carried out concerning the use of NFI data to report within the commitments of the Habitat Directive. The survey covered 13 European countries, accounting for $62 \%$ of forest habitat area. Additionally, case studies were carried out in four countries.

- Results The identification of forest habitat types and the set of quantitative and/or qualitative indicators differ between countries. The use of NFI data is being considered in seven countries and it is expected to increase for the 2013-2018 reporting period. The main challenges reported of use of NFI data are related to the habitat identification and their mapping, and the monitoring frequency, design and costs (i.e. rare or small area habitats).
\end{abstract}

Handling Editor: Tuula Packalen and Klemens Schadauer

Contributions of the co-authors Iciar Alberdi: Experimental design, data analysis and elaboration of the paper

Leónia Nunes: experimental design, literature review and writing the paper

Marko Kovac: experimental design, literature review and writing the paper

Ingrid Bonheme: experimental design and writing the paper

Isabel Cañellas: experimental design and writing the paper

Francisco Castro Rego: experimental design and writing the paper

Susana Dias: experimental design and writing the paper

Inês Duarte experimental design and writing the paper

Monica Notarangelo: experimental design and writing the paper

Maria Rizzo: experimental design and writing the paper

Patrizia Gasparini: experimental design and writing the paper

This article is part of the topical collection on Forest information for bioeconomy outlooks at European level

Iciar Alberdi

alberdi.iciar@inia.es

Extended author information available on the last page of the article 
- Conclusion It is necessary to improve the comparability of the conservation status assessments between countries.

Keywords Forest biodiversity · Function and structure indicators · International reporting • Vegetation · Reference value . Thresholds · Harmonination · NFI

\section{Introduction}

The significance of biodiversity for human wellbeing and the consequences of the continued loss of natural habitats have been recognised in several international conservation policies and initiatives (Bakhtiari et al. 2018) such as the Convention on Biological Diversity (UN 1992), the Millennium Ecosystem Assessment (MEA 2005), the European Natura 2000 network (Wurzel 2008) and the Intergovernmental SciencePolicy Platform on Biodiversity and Ecosystem Services (IPBES 2012).

Europe is a densely populated region with a long history of land use (EC 2015a). Therefore, large-scale conservation is particularly challenging due to the diverse political conditions, social conditions, economic systems and ecological conditions (Orlikowska et al. 2016). The Natura 2000 network is a coherent ecological network of special areas which has been designated to ensure the conservation and sustainable use of nature in Europe. This network is based on the two main legislative instruments for nature conservation in Europe: the Birds (OJEC 1979) and the Habitats (OJEC 1992) Directives (Evans 2012a). Both of these are fundamental for the European Biodiversity Strategy and to accomplish the commitment of the Convention on Biological Diversity (EC 2015a).

The Habitats Directive promotes the maintenance of biodiversity, taking into account economic, social, cultural and regional requirements. Article 11 of this Directive refers to the obligation of Member States to monitor the conservation status of all habitats (as listed in Annex I) and species (as listed in Annex II, IV and V) of Community interest. The conservation status of a habitat is defined as "favourable" in Article 1 of the Habitats Directive when "(i) its natural range and areas it covers within that range are stable or increasing, (ii) the specific structure and functions which are necessary for its long-term maintenance exist and are likely to continue to exist for the foreseeable future, and (iii) the conservation status of its typical species is favourable". The Directive asks for reports every 6years (Article 17) on the species and habitat types to determine whether they present a favourable conservation status. These assessments under Article 17 concern the status across the whole of a biogeographical region within a Member State. However, Article 6 also requires the assessment of the "degree of conservation" of sites according to criteria in Annex III, of a habitat type or species at a specific site (Evans and Arvela 2011).

Member States are therefore obliged by Article 11 to undertake surveys and inventories and these should provide the basis for the Article 17 assessments. Furthermore, Member States are free to choose their means and methods of gathering data and to determine the reference values (threshold values to determine whether the parameters are favourable or unfavourable) (Evans and Arvela 2011). Assessments can be based on a complete survey, estimated based on partial data with some extrapolation and/or modelling, or they can be estimated based on expert opinion with minimal sampling or none at all (EC 2013a).

Forests play a particularly important role in the Natura 2000 network; they hold a significant proportion of Europe's threatened biodiversity and cover around half of the total area of the network (EC 2015b). In fact, in the new EU Forest Strategy (EC 2013b), "forest protection and enhancement of ecosystem services" is referred to as one of its priorities, stating that Member States "should achieve a significant and measurable improvement in the conservation status of forest species and habitats by fully implementing EU nature legislation and ensuring that national forest plans contribute to the adequate management of the Natura 2000 network by 2020”.

The 2015 assessment indicates that the conservation status of forest habitats in the European Union in general is not good, and that there is still much to be done (EC 2015b). However, as Member States are free to establish different monitoring methods, indicators and reference values, aggregating the data from the different countries could prove complex. Currently, most of the Member States base their assessments on simple expert judgement, which highlights the need to further develop or to complement their inventories and monitoring schemes (Ramão 2015).

National Forest Inventories (NFIs) are the main source of information used in most European countries to provide information on forest resources at country and subcountry levels. Most of the NFI sampling designs are based on two-dimensional grids with the monitored plots located at the intersections. However, the spacing of the grid varies considerably, for example from $0.5 \times 1 \mathrm{~km}$ in Belgium (Walonia) or in some Icelandic forests up to $5 \times$ $5 \mathrm{~km}$ in Estonia (Tomppo et al. 2010; Vidal et al. 2016). 
Traditionally, the main focus of NFIs was wood production, although the increasing national and international requirements for information, such as biodiversity data, have led to a broadening of NFI objectives to include new variables (Tomppo et al. 2010; Alberdi et al. 2017).

European NFIs have collaborated on different projects such as COST Action E43, "Harmonisation of National Forest Inventories in Europe: Techniques for Common Reporting" ( 2010), COST Action Usewood (2014) and the ongoing Horizon 2020 project DIABOLO "Distributed, Integrated And Harmonised Forest Information For Bioeconomy Outlooks", all focusing on developing harmonised and thus comparable NFI estimates (Alberdi et al. 2016). Numerous studies have been conducted focusing on the harmonisation of variables such as forest area (Vidal et al. 2008), growing stock (Vidal et al. 2008; Tomter et al. 2012), stem quality (Bosela et al. 2016), deadwood (Rondeux et al. 2012), naturalness (McRoberts et al. 2012), old growth (Alberdi et al. 2013) or ground vegetation (Alberdi et al. 2010). Several authors have highlighted the potential of European NFIs to encompass harmonised estimates for the assessment of the conservation status of forest habitats at different scales (Corona et al. 2011; Chirici et al. 2012; Kovac et al. 2014).

This paper, developed within the framework of the DIABOLO project, aims to (i) compare criteria and methods of reporting under Article 17 of the Habitats Directive in different countries of the EU; (ii) analyse the use and suitability of NFIs to assess the conservation status and/or degree of conservation; (iii) provide recommendations for harmonised assessments in forest habitat types using information provided by NFIs.

\section{Material and methods}

To achieve the proposed objectives, two studies were carried out at different scales: one at European scale, focusing on the information sources, criteria and methods used to assess the conservation status of the forest habitat types in different countries, and a more detailed one, focusing specifically on four countries in which the establishment of indicators and criteria to assess the state of conservation differs. The objective of this second study was twofold: on the one hand, to identify the different particularities when the assessments method differ (from more specific to more general) and on the other, to establish a set of core indicators that would serve as the basis for the questionnaire on which the first study is based.

\subsection{Natura 2000 questionnaire}

A "Forest Habitat Types -Natura 2000" questionnaire was designed to identify the procedures adopted by different countries for the conservation status assessment of forest habitat types (Annex). The survey was sent to NFI representatives of all European countries involved in the Natura 2000 network. Of these 28 countries, there were three in which NFI representatives are not involved in the Natura 2000 reporting process. In other cases, either there was no means to get in contact with those responsible for Natura 2000 reporting or there was simply no reply from them. Responses were received from 13 countries: Austria, Belgium, Finland, France, Germany, Hungary, Italy, Portugal, Romania, Slovakia, Slovenia, Spain and UK (Fig. 1). Respondents to this questionnaire included NFI delegates as well as Natura 2000 correspondents in several countries. These countries have a combined forest area of nearly one hundred million hectares, of which nearly 7 million are Sites of Community Importance in the Natura 2000 Network area, accounting for $62.39 \%$ of the total area of Forest Sites of Community Importance in Europe (Table 1) (European Environment Agency 2016). The smallest forest area in Sites of Community Importance and also the lowest ratio in relation to the total forest area are found in Portugal (0.02). However, if Special Areas of Conservation are considered instead of Sites of Community Importance, the resulting area is 190,856 ha and the ratio of this value related to the national forest area is $5.9 \%$ (Duarte et al. 2016).

The questions were developed to acquire information regarding (i) national forest habitat definitions identifying forest habitat types using a combination of singlechoice and open questions; (ii) the establishment of quantitative and/or qualitative indicators to evaluate the structure and function of the forest habitat types through single-choice questions; (iii) the sources of information for reporting and the scale of the assessments through multi-choice questions; (iv) the use of NFI information through a combination of open-choice and single-choice questions; (v) the national challenges involved in monitoring and reporting the conservation status and the gaps in information using open questions; and (vi) the prospects for future, expected modifications in methods through open questions.

The NFI structural and functional core variables included in the questionnaire to assess the conservation status or degree of conservation of the forest habitat types were the following: composition (trees, shrubs); vegetation functional types (trees, shrubs, ferns, herbaceous); regeneration; tree diameter distribution; oldgrowth trees; stand height; deadwood; non-tree 


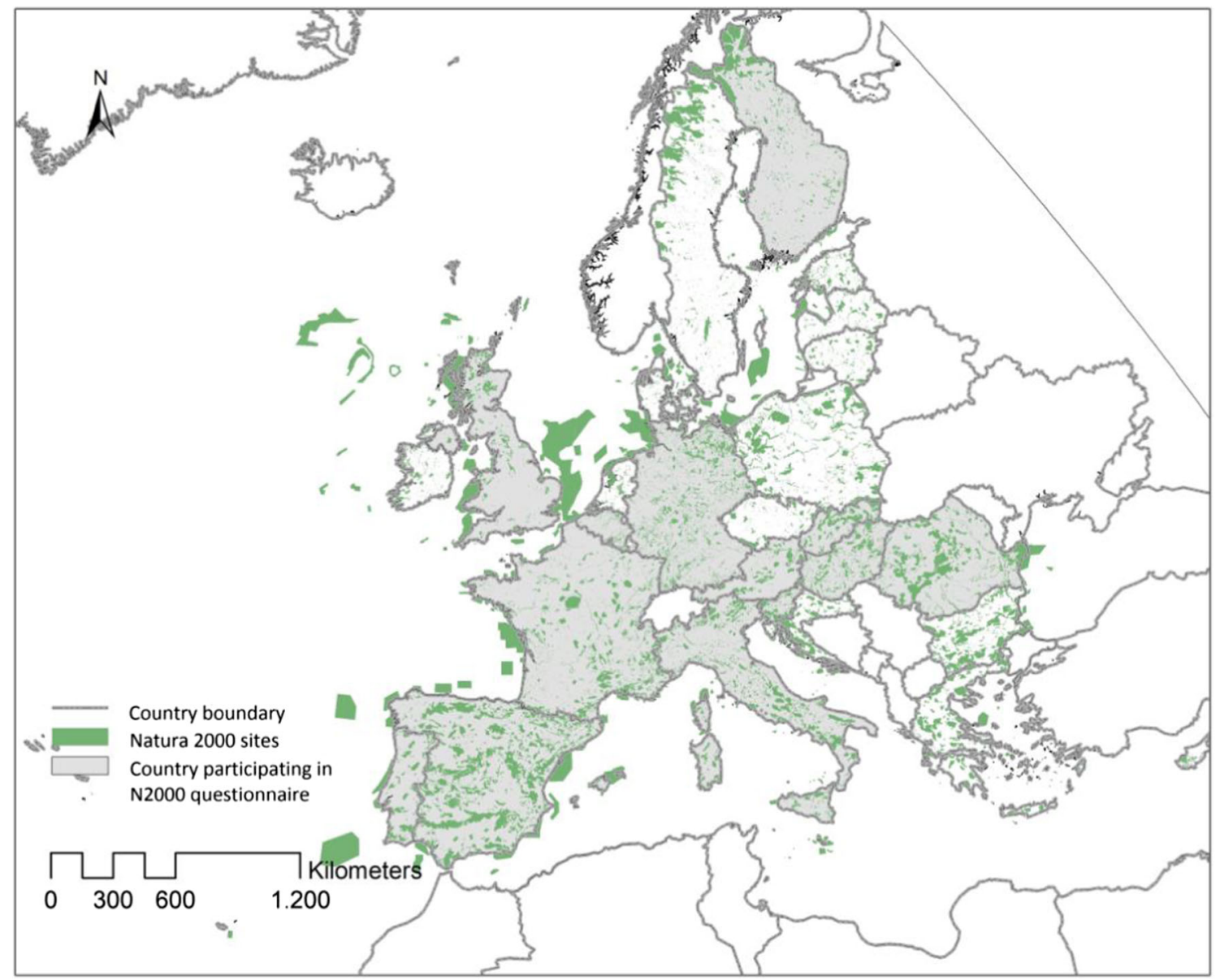

Fig. 1 Map of the countries participating in the Natura 2000 questionnaire (in grey) and Natura 2000 sites of community importance (in green)

vegetation species; invasive species; tree hollows; browsing impact; fire damage; naturalness; soil treatment; others. This selection was performed considering the variables measured in NFIs and the list of indicators was drawn up from four case studies.

\subsection{Case studies}

The methods, indicators and their thresholds to assess the conservation status of forest habitat types were studied in depth in four countries. These countries were characterised as they differed regarding the status of the establishment of indicators and criteria to assess the state of conservation of the forest habitat types, from more specific to more general: (i) Country considering different indicators and thresholds for each forest habitat type: Spain; (ii) Country considering a homogeneous set of indicators for each forest habitat type: Italy; (iii) Country considering a homogeneous set of indicators for most forest habitat types with specific exceptions for certain habitats: Portugal; (vi) Country without a specific list of indicators established: Slovenia.
A list of all the structural and functional indicators used for the conservation assessment of each forest habitat type was elaborated. These indicators were classified into groups based on the object of the estimation, identifying their suitability for estimation using only NFI data (high, medium or low possibility of being estimated using NFI information).

\section{Results}

\subsection{Forest habitat types: definitions and identification}

All countries involved in the questionnaire use supplementary national definitions to identify forest habitat types. Only two countries (Slovenia and Slovakia) had difficulty specifying whether the definitions contained new specifications, although they provided national reports for interpreting forest habitat types.

Information from these reports is available to the public in all countries. Most of the report references can be found in Evans (2012b) with the exception of those updated after 2012, 
Table 1 Forested area of the Natura 2000 Network for countries participating in the questionnaire on "Forest Habitat Types -Natura 2000"

\begin{tabular}{lllll}
\hline Country & $\begin{array}{l}\text { Forest area } \\
(1000 \mathrm{ha})\end{array}$ & $\begin{array}{l}\text { Forest SCI area } \\
(1000 \mathrm{ha})\end{array}$ & $\begin{array}{l}\text { Ratio forest SCI } \\
\text { area/national } \\
\text { forest area (\%) }\end{array}$ & $\begin{array}{l}\text { Ratio forest SCI } \\
\text { area/European forest } \\
\text { habitat types area (\%) }\end{array}$ \\
\hline Austria & 3860 & 184 & 4.76 & 1.71 \\
Belgium & 681 & 102 & 14.92 & 0.95 \\
Finland & 22,218 & 1439 & 6.48 & 13.40 \\
France & 16,424 & 164 & 1.00 & 1.53 \\
Germany & 11,409 & 777 & 6.81 & 7.23 \\
Hungary & 2046 & 441 & 21.54 & 4.11 \\
Italy & 9028 & 1803 & 19.97 & 16.79 \\
Portugal & 3239 & 1 & 0.02 & 0.01 \\
Romania & 6515 & 144 & 2.22 & 1.34 \\
Slovakia & 1939 & 238 & 12.27 & 2.22 \\
Slovenia & 1247 & 238 & 19.10 & 2.22 \\
Spain & 18,247 & 1151 & 6.31 & 10.72 \\
UK & 3059 & 19 & 0.61 & 0.17 \\
Total & 99,913 & 6700 & & 62.39 \\
\hline
\end{tabular}

Forest area from SoEF (2015). Forest habitat type area in Sites of Community Importance (SCI) from https:// www.eea.europa.eu/data-and-maps/data/natura-8 (2016) as is the case of the 13 forest habitat types for Hungary (Haraszthy 2014).

For the identification of forest habitat types, nearly half of the participating countries only consider current vegetation, while the other half consider both current and natural potential vegetation (Table 2). Only one country (France) considers the natural potential vegetation. In terms of percentage of the forest area of the Natura 2000 network under the Habitats Directive (estimated as the sum of the forest area of Sites of Community Importance), corresponding to the countries participating in the survey, $75 \%$ considers only the current vegetation, 2\% considers natural potential vegetation and $23 \%$ considers both (European Environment Agency 2016).

\subsection{Quantitative and/or qualitative indicators to evaluate the structure/functions of the Natura 2000 forest habitat types}

Most countries answering this questionnaire have established quantitative and/or qualitative indicators to evaluate the

Table 2 Identification of forest habitat types by countries participating in the questionnaire

\begin{tabular}{lcc}
\hline & No. of countries & $\begin{array}{l}\text { Forest habitat } \\
\text { types area (1000 ha) }\end{array}$ \\
\hline Current vegetation & 6 & 4997 \\
Natural potential vegetation & 1 & 164 \\
Both & 6 & 1539 \\
Total & 13 & 6700 \\
\hline
\end{tabular}

structure/functions of the Natura 2000 forest habitat type with the exception of Portugal and Slovenia. However, Portugal has a list of occurrence of typical dominant species compiled using expert judgment.

Other crucial information for harmonisation purposes concerns whether the set of indicators considered by the different countries are the same for every forest habitat type or whether specific indicators exist for each one. Only four countries (accounting for $45 \%$ of the forest area of the Sites of Community Importance of the participating countries) consider a different set of indicators for each forest habitat type: Austria, Finland, Slovenia and Spain. Additionally, there are two forest habitat type exceptions in the case of Slovakia (European Environment Agency 2016).

In the countries which consider a homogenous set of indicators, the indicator thresholds used for each forest habitat type may differ from one country to another. However, these thresholds are not generally specified and are evaluated by experts. This is the case in most of the countries, even those which have a specific set of indicators for each forest habitat type. For instance, in Spain, a dead wood indicator was proposed in nine forest habitat types, for which four different recommended inventorying methodologies are described with different thresholds indicating favorable conservation status. This threshold is $30 \mathrm{~m}^{3}$ per hectare in "Atlantic acidophilous beech forests with Ilex and sometimes also Taxus in the shrublayer (Quercion robori-petraeae or Ilici-Fagenion)" (9120 forest habitat type) while in "(Sub-) Mediterranean pine forests with endemic black pines" (9530 forest habitat type), the indication is four or more standing dead trees per hectare and six or more lying trees with diameters greater than $30 \mathrm{~cm}$ (MARM 2009). 
Table 3 Percentage of forest area of Sites of Community Importance (SCI) in Natura 2000 depending on the method used to assess the conservation status of the forest habitat types (FHT) in the 2007-2012 reporting period

Method used to assess the conservation status

\subsection{Sources of information used for the conservation status of forest habitat types evaluated in 2007-2012 reports}

The majority of the countries involved in this questionnaire (seven in all, accounting for $71 \%$ of the forest area of Sites of Community Importance) based most of their assessment of the conservation status of the forest habitat types in the 20072012 reporting period on expert knowledge with limited data (according to the methods description of the Art. 17 guidelines (Evans and Arvela 2011)) (Table 3). Austria and Belgium based their assessment of structure and function of the forest habitats mainly on NFI data. In Romania, the evaluation used NFIs as well as forest management plan data. In this country, management plans are taken into consideration by experts to evaluate typical herbaceous species, pressures and threats. The UK used an intermediate method, employing expert knowledge along with data from NFIs as well as other inventories. Slovenia supported its assessments with data from NFI and forest management units. These data, however, are not consistent in terms of time period.

Furthermore, the minimum scale of the assessment in which NFI data is used differs among countries (afterwards, information is aggregated by habitat type and biogeographical region). Six countries assess the conservation status at plot or stand level (accounting for 30\% of the forest area of Sites of Community Importance), four countries (Hungary, Italy, Portugal and Spain) at site level (48\% of the forest area in Sites of Community Importance) and three countries (Slovenia, Germany and France) at biogeographical level (22\% of the forest area of the Sites of Community Importance) (European Environment Agency 2016) (Fig. 2).

\subsection{The use of NFI information}

NFI information is currently being used to evaluate the conservation status in at least seven countries for the 2013-2018 reporting period: Belgium, Germany, France, Romania and UK, among those considering a homogenous set of indicators, and Austria and Finland among those considering a heterogeneous list. The forest habitat type assessment can be mainly or partially based on NFI information. Additionally, the scale at which the conservation status assessments are conducted varies from one country to another.

The identification of forest habitat types in seven countries (accounting for $49 \%$ of the forest area of Sites of Community Importance of the participating countries; European Environment Agency 2016) is based on or supported by information from the NFIs. Romania identifies the forest habitat types after the field work (according to the data recorded), while the others determine them in the field (as France and Germany), although some (Austria, Belgium and Finland) validate this decision with additional NFI data following the field work.

The variables recorded in NFIs to identify the forest habitat types are as follows: natural potential vegetation, forest growth region or ecoregion, tree species composition, indicator species, ground vegetation, soil classification and topography.

The structural and functional indicators considered by the different countries differ substantially. In Spain, a set of indicators have been defined by forest habitat type. Several of these indicators could be estimated using information from the NFI (determined by NFI experts in the case studies).

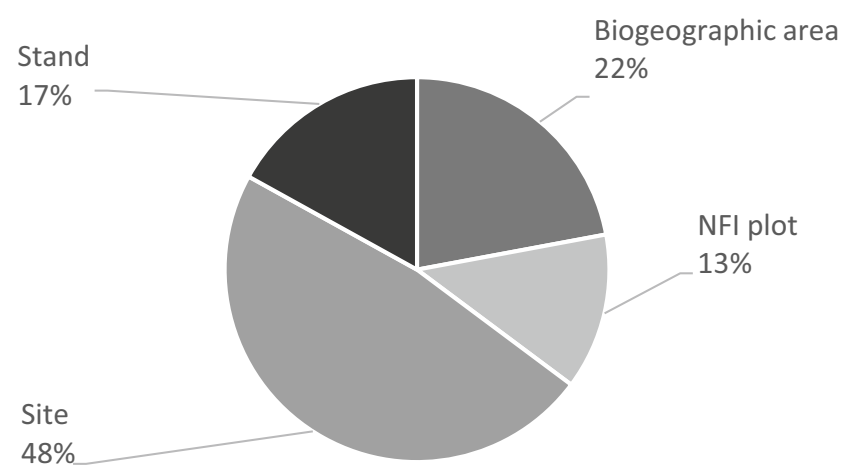

Fig. 2 Scale at which the assessments of conservation status of the forest habitat types in the 2007-2012 reporting period were conducted. Percentage in terms of forest area of Sites of Community Importance 
Taking into account the seven countries previously mentioned, along with Spain, the percentage of countries considering the core variables identified in the questionnaire was calculated.

Tree diameter distribution is considered by all countries involved in this enquiry and stand height is considered by $75 \%$ of the countries (indicators reflecting the horizontal and vertical stand structure). Non-tree vegetation species are considered by $88 \%$ of the countries while tree composition is considered by $75 \%$ of them. Regeneration and dead wood are also key parameters ( $63 \%$ of the countries). Additionally, half of the countries also consider disturbances such as forest fires, invasive species and vegetation functional groups of trees, ferns and herbaceous plants. The percentages for other indicators are below 50\% (Fig. 3).

Other indicators reported by the different countries are:

- France: volume of trees $\mathrm{dbh}>67.5 \mathrm{~cm}$ for indigenous species, diameter of the final decile of the number of stems, area by number of non-indigenous and invasive species, part of non-indigenous species in the basal area, area planted

- Germany: development phases, layers of forest cover, pressures

- Spain: the main indicators that could be estimated using the NFI are related with tree age, fellings, tree growth and tree health status

- UK: occupancy of nativeness, age distribution of species, vertical structure of the woodland (layers), number of native tree and/or shrub species, tree pests and diseases, veteran trees

\subsection{Main challenges and gaps in information}

The main challenges reported by the countries involved in monitoring and reporting the conservation status of forest habitat types were related to their identification and their mapping, the monitoring design and costs (especially for rare forest habitat types), the identification of effective indicators, the definition of a reference status, the aggregation of indicator values to a global conservation status and to maintain the conservation status of these habitats up to date (Fig. 4). Austria also highlights the fact that due to the dimensions of the NFI plot, some of the indicators used for structure and functions may produce a bias towards less favorable values for conservation status.

Regarding the mismatch between the available data and the information needs of the decision-makers, countries highlighted important gaps in the information, many of which coincide with the main challenges reported (Fig. 5). One of them is the problem of monitoring frequency or monitoring of rare or low area forest habitat types for which estimates might not be representative or show a high degree of uncertainty. In this case, additional data sources are needed. Another recurrent aspect is the assessment scale; NFIs may not provide relevant information for each Natura 2000 site. Certain crucial biodiversity indicators such as game damage or soil integrity are difficult to assess (either because of the nature of the data collected, or because the indicators are difficult to elaborate).

It is also important to mention that the monitoring methods employed may not be sufficiently sensitive to detect slow changes in habitat conservation status/
Fig. 3 Structural and functional indicators considered to assess the conservation status of forest habitat types using information from NFIs or countries in which the indicators can partially be estimated from NFI information. Percentage in terms of number of countries. Structural indicators in dark grey, functional indicators in light grey, indicators that could be considered either structural or functional in white

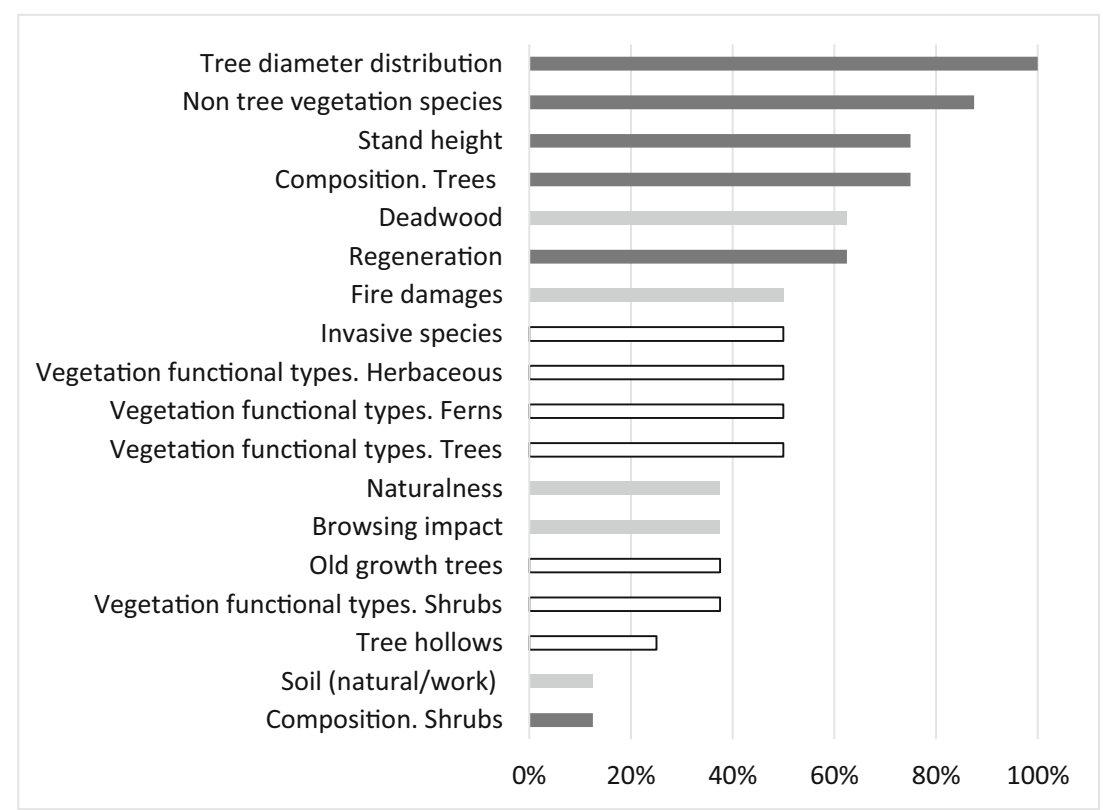


Fig. 4 Percentage of area of forest habitat types in Natura 2000 and in the number of countries considering the different principal challenges associated with assessing the conservation status of the different forest habitat types

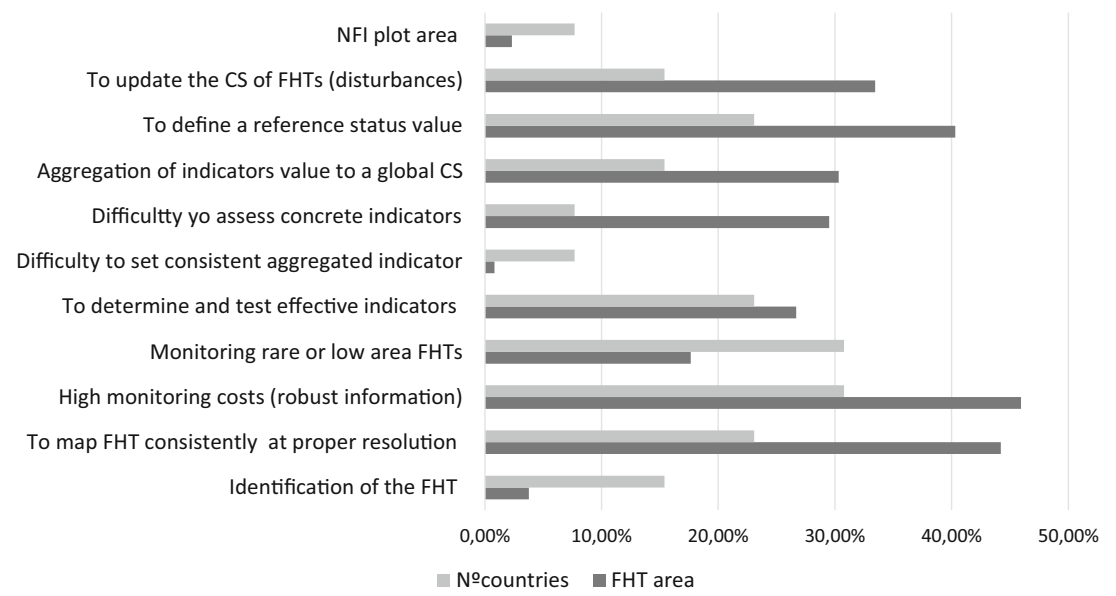

condition and therefore the impacts of policy measures are not identified, resulting in a lack of information for decision-makers. The difficulty involved in explaining and interpreting the value of species and maintenance of biodiversity through indicators for decision-makers is also highlighted.

\subsection{Prospects for the future}

In six countries (accounting for $65 \%$ of forest area of the Sites of Community Importance; European Environment Agency 2016) changes in the forest habitat conservation assessment are expected for the next reporting period (2013-2018), while only three countries $(15 \%$ of forest area of the Sites of Community Importance) expect no major changes (Fig. 6). In four countries, there is a possibility that the NFI will be considered or implemented (France, Spain, Portugal and UK). In Portugal, NFI data will be considered for habitat identification and probably for conservation status assessment. In Hungary, Romania and Slovakia, field data will be taken into account. In Italy, a new manual for evaluation and monitoring was published which provides updated common guidelines for monitoring at regional (administrative regions) level (Angelini et al. 2016).

\subsection{Case studies: structural and functional indicators}

A total of 172 structural and functional indicators to assess forest habitat types were identified and classified into groups (Table 4). The status and definition of the conservation indicators differed among countries.

In Italy, the assessment of conservation status is mainly based on expert judgement, and the national guidelines do not provide a list of specific indicators for Natura 2000 habitats and related thresholds or reference values for the favourable/unfavourable classes. However, a list of 11 recommended structural and functional indicators for the main habitat groups is provided by the national guidelines on assessment and reporting under Article 17 of the Habitats Directive. In Italy, the NFI classification of forest vegetation into forest categories is consistent either with CORINE Forest Habitat classification scheme (EC 1991) and EUNIS Habitat Classification (Rodwell et al. 1998), and this helps to assign NFI plots to a forest habitat type as defined by Natura 2000. As a consequence, the information provided by the NFI could be used to estimate some of the recommended indicators for some habitats at the biogeographical scale.

In Portugal, the assessment of the conservation status is mainly based on expert opinion. Structure and function criteria for evaluation of a habitat type is in the process of
Fig. 5 Percentage of the area of forest habitat types in Natura 2000 and in the number of countries considering main gaps in the assessment of the conservation status of the different forest habitat types

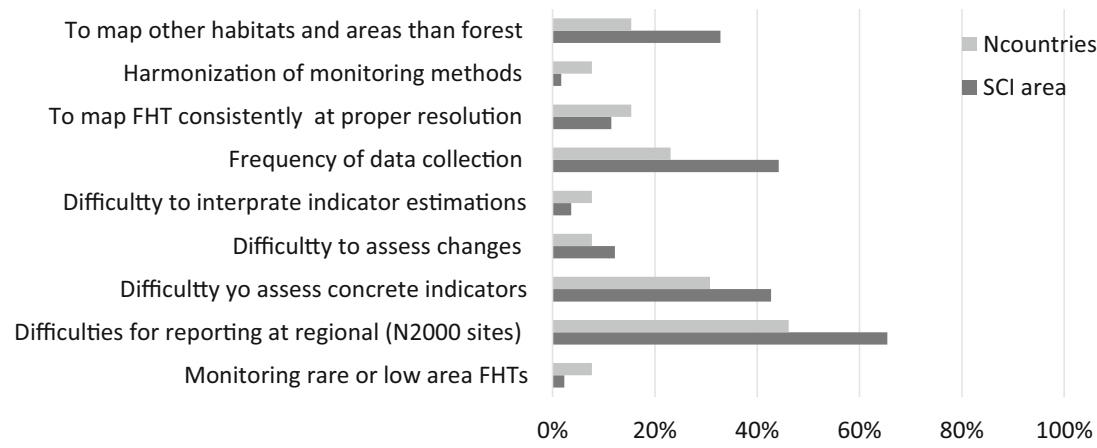


Fig. 6 Expected changes in the methodology for habitat assessment in the 2013-2018 reporting period, referring to the number of countries and forest area of Sites of Community Importance

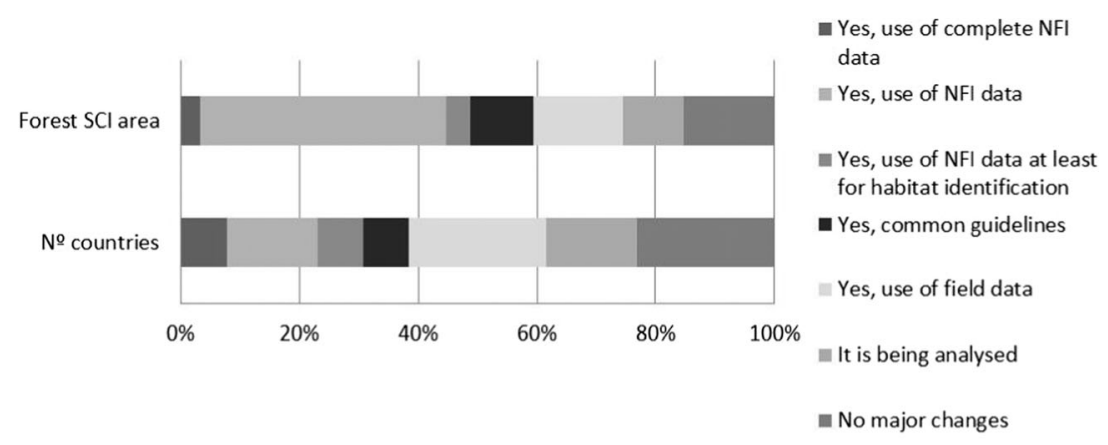

development but not yet available. Generic indicators have been determined for all forest habitat types and there are also specific indicators for some forest habitat types. From the 172 indicators identified, 61 could be determined for the forest habitat types occurring in Portugal with information available from the NFI.

In Slovenia, the method used for assessment of forest habitat types is largely based on expert judgement. Area, structure, function and prospective criteria for evaluation of habitat types are currently under development but not yet available for the Slovenian system. Although there are no detailed indicators for functions and structure, future prospects and threats upon which the conservation status is assessed, several indicators such as tree species composition, presence of dominant species, development phases and vertical structure (even-aged vs uneven aged) are generally considered in the experts' judgements.

In Spain, the assessment of the conservation status of forest habitats has been based mainly on expert judgement in the last reporting period (2007-2012). However, a set of specific indicators have been defined for each forest habitat type. Specific indicators range between five and 25 , for each forest habitat
Table 4 Number of different structural and functional indicators grouped by the objective of the estimation identified in Italy, Portugal, Slovenia and Spain, aiming to assess the conservation status of the forest habitat types and the possibility of estimation using NFI data (considering field protocols of Italy, Portugal, Slovenia and Spain)

\begin{tabular}{lll}
\hline Group of indicators & $\begin{array}{l}\text { Number of } \\
\text { indicators }\end{array}$ & $\begin{array}{l}\text { Possibility of estimation } \\
\text { with NFI data }\end{array}$ \\
\hline Alien plant species & 2 & High \\
Animal species presence & 16 & Low \\
Fellings & 1 & High \\
Deadwood & 5 & High \\
Disturbances & 5 & High \\
Endangered species & 1 & Medium \\
Floristic composition & 16 & Medium \\
Herbivory & 7 & Medium \\
Horizontal structure & 17 & High \\
Naturalness & 2 & Medium \\
Old-growth trees & 2 & High \\
Regeneration & 12 & High \\
Seeds and/or seedlings production/survival & 8 & Medium \\
Shrub composition and structure & 1 & High \\
Soil & 3 & Medium \\
Spatial indicators & 17 & Low \\
Stand age & 2 & High \\
Tree composition & 30 & High \\
Genetic information & 2 & Low \\
Tree growth & 4 & High \\
Tree health status & 5 & Medium \\
Tree stress & 4 & Low \\
Vertical structure & 5 & High \\
Water flows and regime & 5 & Low \\
Total & 172 & \\
\hline & & \\
\hline
\end{tabular}


type, with a total of 232 indicators of which, 162 can be considered as different if aspects such as units or if data is provided by unit area or not, are not considered. For each indicator, specific thresholds have been set to assess the conservation status of the habitat. Sixty-five percent of the indicators could be estimated using information from the Spanish NFI. The indicators related with reproductive capacity of vegetation and survival of seeds, genetic information of vegetation species, animal composition such as bird communities or invertebrates, water stress, soil information and spatial indicators are those which require ancillary information (Espinosa et al. 2018).

\subsection{Proposal for set of general indicators}

Based on the information available in the NFIs, the case studies and the questionnaire results, a list of common indicators for every forest habitat type that could be estimated using the information provided by NFIs is proposed, independent of the establishment of specific indicators for each forest habitat type.

The common indicators included in this first attempt at a list are as follows: tree species richness; non-native species; regeneration; diameter distribution; large trees; vertical structural diversity; deadwood; tree cavities; browsing damage; forest disturbances (fires); soil treatment; tree pests and diseases.

\section{Discussion}

The results from both the questionnaire and case studies confirm that further effort is required to enable comparison of the information obtained among the different countries for reporting under Article 17 of the Habitats Directive, which assesses whether species and habitat types present a favourable conservation status.

As regards the identification and determination of the natural range and areas covered by countries, an interpretation manual was produced by the European Commission in association with experts from the Member States in order to establish a common understanding of habitats (EC 2013b). However, our questionnaire revealed that almost all the countries are using supplementary specifications to identify forest habitat types. Moreover, in their identification, almost half of the countries only take into consideration the current vegetation while the other half also consider natural potential vegetation. This variation from one Member State to another in terms of how they interpret the habitat types was detected by Evans (2010), who provided several examples of differing interpretations which, in some cases, could even differ between regions within the same country. In this regard it should also be noted that two countries (Austria and Slovakia) described the identification of forest habitat types as challenging, whilst another three (Italy, Portugal and Spain) highlighted the need for consistent mapping of forest habitat types at an appropriate resolution in order to monitor changes.

Most of the countries involved in this questionnaire determined quantitative and/or qualitative indicators to evaluate the structure and function of the forest habitat types. However, no consensus exists among the countries with regard to the monitoring methods or the indicators which should be used to assess the favourable conservation status of forest habitat types. In fact, as reflected in the case studies and questionnaire, a variety of approaches have been adopted by the different countries although assessments carried out in most of the countries are mainly based on expert judgement. It is interesting that in some countries the set of indicators considered is the same for all the forest habitat types, whilst in others (four countries, although these account for $45 \%$ of the forest area in Sites of Community Importance of the surveyed countries), the indicators depend on the forest habitat type. Moreover, the proposed monitoring methods can differ between forest habitat types within the same country (as is currently the case in Spain; MARM 2009). Cantarello and Newton (2008) highlighted the differences between the assessments from Austria and UK (Ellmauer 2005; JNCC 2004). Particularly surprising is the fact that none of the participating countries in our survey used the same set of indicators, although some are frequently used. Several attempts have been made at drawing up a set of indicators to assess favourable conservation status, as in Cantarello and Newton (2008), who suggested that biodiversity indicators developed to assess sustainable forest management could be considered, or Kovac et al. (2016), who designed a set of biodiversity and conservation status indicators and evaluated their suitability in the three largest forest habitat types in Slovenia. A study of sustainable forest management indicators was also conducted by Larsson et al. (2001). However, the main challenge according to the different countries involved in the survey is the urgent need to provide and test effective indicators and thresholds at national level.

Furthermore, the absence of clear thresholds for the conservation status indicators is another important element that must be addressed. The search for suitable threshold values should begin with indicator distribution function analyses at bioregional levels. Studies reveal that the thresholds are highly dependent on the niches of (typical) plant and animal species of each habitat type (Müller and Bütler 2010), which remain unknown. Slow progress is also significant for the development of multi-variable decision-making models to be used for overall assessment of the conservation status of forest habitat types at all spatial scales.

Progress is also slow with regard to the development of a methodology for obtaining a global conservation status value 
through the aggregation of the different indicators. Although some simple models have been presented (Velázquez et al. 2010), there is room for the development of qualitative and quantitative models to be used for objective assessments of the conservation status of forest habitat types.

Increased coordination across national boundaries is widely believed to be more cost effective compared to independent national planning (Bakhtiari et al. 2018). Given the evident need to improve the comparability of assessments among Member States, the use and suitability of NFIs were evaluated as a tool to assess the conservation status of forest habitat types and/or the degree of conservation, which in recent years has been the focus of important harmonisation efforts. Moreover, since NFIs are increasingly used to monitor other types of wooded land area (Vidal et al. 2016), NFI data can be used for other habitats apart from forests, such as semi-natural dry grasslands and scrubland facies like habitat type 6310 "Dehesas with evergreen Quercus spp." or for temperate heath and scrub, sclerophyllous scrub, or semi-natural dry grasslands and scrubland facies habitats. NFIs, if conducted successively and at appropriate time intervals, provide diverse, long-term information on forests allowing trends to be analysed. The use of NFIs will mean a step towards greater objectivity rather than the commonly used assessments based on expert knowledge (Ramão 2015). Our study found that NFIs are either already used or could be used as the main source of information in seven countries, and responses to the questionnaire revealed that the NFIs will be considered for future assessments in four more countries. This prospect highlights the importance of the NFI harmonisation processes.

Winter et al. (2008) pointed out that to harmonise any indicator used for forest biodiversity monitoring, it is first necessary to harmonise the methods employed. The analysis of the quantitative and/or qualitative indicators used to evaluate the structure and function of forest habitat types by countries revealed that the indicators most used by countries capable of utilizing NFI data as the main source of information for at least some of the established indicators are horizontal and vertical structure indicators (tree diameter distribution and stand height), composition (tree species, but also non-tree vegetation species), regeneration and important disturbances (such as forest fires). The horizontal and vertical structure indicators can easily be harmonised, as related definitions, thresholds and characteristics, e.g. tree compartments such as the stem, have been commonly agreed upon and developed (Gschwantner et al. 2009). Tree species composition indicators will also be simple to harmonise as European NFIs are used to monitor every species (San-Miguel-Ayanz et al. 2016). However, the composition of non-tree vegetation species would not only require harmonisation efforts but also possibly the modification of field protocols in some countries, as monitored species lists differ depending on the objectives of the NFIs. Moreover, very few NFIs include a comprehensive ground vegetation species inventory (Alberdi et al. 2010). Regeneration is a key aspect of the conservation status assessment. Monitoring methods and estimates for regeneration are difficult to harmonise at present (Chirici et al. 2012), although increasing effort is being directed towards this aspect within the framework of the DIABOLO project (http://diaboloproject.eu/). Forest disturbances are generally recorded in European NFIs, although again, there is a need to harmonise data; this is a task which is also currently under analysis through the DIABOLO project.

Hence, European NFIs provide a promising source of information and could form the basis for the assessment of conservation status and/or degree of conservation in forests, bearing in mind that not only do they represent the largest network of sample plots in Europe, but they are also capable of providing harmonised indicators at European scale.

Even so, it is evident from the case studies and reflected in the challenges discussed above, that not all the necessary indicators can be estimated from NFIs alone. Thus, ancillary information is required, especially spatial indicators (such as fragmentation or species connectivity) and fauna species (such as species indicators or bird communities or invertebrate species). Additionally, the dimensions of NFI plots differ between countries, and for some indicators this could produce a bias towards a less favorable status. In this regard, an example could be the strong dependence of species richness on the number of individuals and the area sampled (Gleason 1922; Preston 1948) or the influence of having a plot design consisting of concentric circles (used in several NFIs) for the estimation of certain structural indicators (Vidal et al. 2016).

However, structural and functional indicators and especially desired portrayals of forest habitat type may be inaccurate if they are considered static over time, not reflecting the dynamics of vegetation succession (temporal changes in the vegetation structure and species composition) (Kovac et al. 2017). It could be argued that this demonstrates the need for expert assessments, although a more objective solution would be to consider the extensive information provided by NFIs, such as forest disturbances, tree diameter distribution, or regeneration. Thus, the conservation approach should take into account the natural dynamics over time and space, as proposed by the author, which could be done by combining the existing information.

There is a need for further efforts to harmonise the assessment of forest habitat types using information provided by NFIs. A preliminary list of indicators has been drawn up, taking into consideration the information available in the NFIs as well as the findings of this paper.

As mentioned previously, our questionnaire did not consider thresholds for each indicator. Harmonisation of indicators for regeneration and disturbances, for example, would be of particular interest. Cantarello and Newton (2008) made reference to the difficulty involved in defining a "core set" of 
generally applicable indicators for monitoring Natura 2000 forest sites, or even for similar forest types. It is therefore necessary to conduct further tests with different indicators. Furthermore, data distribution analysis for each indicator would be essential in order to establish thresholds.

The structure and function of the habitats require site-based monitoring, which could be done using the NFIs. In fact, the primary strength of large-scale inventories as NFIs is a scientifically rigorous design-based statistical estimation method that produces estimates of forest attributes with known sampling error and quantifiable measurement error (Barrett and Gray 2011). However, Barrett and Gray (2011) also highlight that one of the main weaknesses includes low power for small area estimates. This fact has been stated by several countries (i.e. case of rare forest habitat types or those which only occupy a limited area) meaning a low number of sampling plots monitored for those areas leading to imprecise estimates. So, further monitoring with increased plot density or applying a stratified sampling would be required. In the case of site-scale reporting, the analysis of the number and density of NFI plots may be necessary to avoid high levels of uncertainty. However, it should be borne in mind that to obtain robust information at regional scale, the cost of monitoring will be high. Hence, further studies focusing on monitoring needs depending on the indicators and information to be recorded should be undertaken.

The establishment of a threshold (appropriate to the context of each country and forest type) for each indicator will help Member States to adapt the recommendations to their respective NFIs in the future. It is important that the way in which data is reported enables comparative analyses to be performed at European scale. Furthermore, the integration of these variables in the NFI survey could provide further benefits in terms of increased efficiency of forest monitoring.

Finally, since the Natura 2000 network involves an integrative approach towards conservation, social and economic considerations are taken into account, including sustainable development (Winkel et al. 2015). Hence, the inclusion of social indicators should be considered. Sievänen (2013) highlighted the need for further development of social indicators in the monitoring and management of sustainable forestry and forest use. NFI sample plots could also contribute to the provision of information aimed at integrating this social dimension of forests (Hegetschweiler et al. 2017; Jensen et al. 2008), although considerable effort would be required to integrate this aspect in most of the European NFIs (Sievänen 2013).

\section{Conclusions}

The results highlight the differences and similarities between different countries in reporting forest habitat types within the commitments of the Habitat Directive.
The identification of the forest habitat types as well as the methods and data used for the assessment differs from one country to another; hence, it would be necessary to improve the comparability of this information between countries.

NFIs could contribute towards a more objective assessment as they provide diverse, long-term information on forests producing estimates of forest attributes with known sampling error and allowing trends to be analysed. Nevertheless, the use of NFIs also faces several challenges such us the habitat identification and mapping, and the monitoring frequency, design and costs (i.e. rare or small area habitats).

A set of general indicators that can be estimated using NFI data could contribute to the harmonisation of the conservation status assessment in forest habitat types.

Acknowledgements We wish to thank all those who made this study possibly by answering the questionnaires on "Forest Habitat Types Natura 2000" questionnaire from DIABOLO and ENFIN networks:

Alexandra Freudenschuss for Austria; Franz Koiher for Germany; Gheorghe Marin for Romania; Roberto Vallejo and Rafael Hidalgo for Spain; Ildikó Varga and László Kolozs for Hungary; Markus Lier for Finland; Michal Bosela and Vladimír Šeben̆ for Slovenia; Philippe Lejeune for Belgium; and Tom Wilson, Ben Dictchburn and Eric Casella for UK.

We would also like to thank other NFI correspondents for their answers: John Redmond for Ireland, Milos Kucera for Czech Republic, Jura Cavlovic for Croatia and Heino Polley for Germany.

And finally, to Vivian Kvist Johannsen, Sara Holgrem and Laura Fernández for their suggestions and support on the questionnaire design. We also thank Adam Collins for his help in editing this paper.

Funding The research was funded by the project DIABOLO (European Union's Horizon 2020 research and innovation programme under grant agreement no. 633464).

Data availability The datasets generated and/or analysed during the current study are available from the corresponding author on reasonable request. The authors are considering to make the dataset available in a public repository upon acceptance from the national responsible of each questionnaire and the Head of each one of the involved National Forest Inventories (Austria, Belgium, Finland, France, Germany, Hungary, Italy, Portugal, Romania, Slovakia, Slovenia, Spain and UK).

\section{Compliance with ethical standards}

Conflicts of interest The authors declare that they have no conflict of interest.

\section{Appendix. Forest Habitat Types (FHT) -Natura 2000 questionnaire}

1. Have your country used supplementary national definitions to identify FHT with additional specifications? Yes / No (Please if possible, add the references or associated literature)

2. Do you identify the FHT by the current or the natural potential vegetation? Current / Potential/ or both? 
3. Have your country established quantitative or/and qualitative indicators to evaluate the structure of the N2000 FHT? Yes/No

4. Have your country established quantitative or/and qualitative indicators to evaluate functions of the N2000 FHT? Yes / No

5. If yes (questions 3 or 4). Do you use a homogenous set of indicators for all habitats? Yes / No

6. Which data or information were used for the conservation status of FHT evaluated in 2007-2012 reporting? Data from NFIs/ From others inventories/specific inventories on the site/Mainly experts evaluation

7. At what scale were the assessments of conservation status conducted? Stand level/sites level/others

8. Will the methodology for habitats evaluation change in the 2013-18 reporting? Which aspects will change?

9. Is your NFI information used in your country to assess the conservation status of N2000 sites in FHT? Yes /No

10. Is your NFI information used to assess the overall conservation status of the FHT in the Article 17 reporting? Yes / No

11. If yes (question 9) for what parameters of N2000 reporting? (according to Art.17 of the Habitats Directive)

\section{a. Identify area/range of different habitats Yes/No}

i. If yes (question 11a). Do you identify the forest habitat type in the field? Yes/no

ii. If yes (question 11ai), is the identification made on all forests in the country or in specific forest areas (e.g. SACs, natural areas...)? What parts of the forest is excluded?

iii. Do you identify FHT from the field data after the field work? Collected for other purposes?

1. If yes (questions 11aiii), what variables and what methods are used for this purpose?

b. Evaluate structure and functions of the habitats? Yes/ No

i. If yes (7b) what core variables from NFI data set have been used?

\section{Composition}

a. Trees (Yes/No)

b. Shrubs (Yes/No)

2. Vegetation functional types
a. Trees (Yes/No)
b. Shrubs (Yes/No)
c. Ferns (Yes/No)
d. Herbaceous (Yes/No)

3. Regeneration $(\mathrm{Yes} / \mathrm{No})$

4. Tree diameter distribution (Yes/No)

5. Old growth trees $(\mathrm{Yes} / \mathrm{No})$

6. Stand height (Yes/No)

7. Deadwood (Yes/No)

8. Non tree vegetation species (Yes/No)

9. Invasive species (Yes/No)

10. Tree hollows (Yes/No)

11. Browsing impact (Yes/No)

12. Fire damages (Yes/No)

13. Naturalness (Yes/No)

14. Soil (natural/work) (Yes/No)

15. Others: (please specify)

ii. If possible, please provide a list of indicators and thresholds assessed through NFI data and/or related published documents.

12. What are the main challenges in monitoring and reporting conservation status of FHT? Please specify.

13. Is there a mismatch between the data you can provide and the information needs of the decision-makers? If yes, please specify the main gaps.

Open Access This article is distributed under the terms of the Creative Commons Attribution 4.0 International License (http:// creativecommons.org/licenses/by/4.0/), which permits unrestricted use, distribution, and reproduction in any medium, provided you give appropriate credit to the original author(s) and the source, provide a link to the Creative Commons license, and indicate if changes were made.

\section{References}

Alberdi I, Condés S, Martínez-Millán J (2010) A review of monitoring and assessing ground vegetation biodiversity in national forest inventories. Environ Monit Assess 164(1):649-676. https://doi.org/ 10.1007/s10661-009-0919-4

Alberdi I, Cañellas I, Hernández L, Condés S (2013) A new method for the identification of old-growth trees in National Forest Inventories: application to Pinus halepensis Mill. stands in Spain. Ann of For Sci 70(3):277-285

Alberdi I, Gschwantner T, Bosela M, Redmond J, Riedel T, Snorrason A, Gasparini P, Braendli UB, Fridman J, Tomter S, Kulbokas G, Lanz A, Vidal C (2016) 3. Harmonisation of data and information on the potential supply of wood resources. In: Vidal C, Alberdi I, Hernández L, Redmond J (eds) National Forest Inventories - assessment of wood availability and use. Springer, Berlin

Alberdi I, Vallejo R, Álvarez-González JG, Condés S, González-Ferreiro E, Guerrero S, Hernández L, Martínez M, Montes F, Oliveira N, Pasalodos-Tato M, Robla E, Ruiz-González AD, SánchezGonzález M, Sandoval V, San Miguel A, Sixto H, Cañellas I (2017) The multi-objective Spanish National Forest Inventory. Forest Syst 26(2):04

Angelini P, Casella L, Grignetti A, Genovesi P (2016) Handbook for monitoring species and habitats of community interest (Council Directive 92/43/EEC) in Italy: habitat types. ISPRA, Series Handbooks and Guidelines, 142/2016 
Bakhtiari F, Jacobsen JB, Thorsen BJ, Lundhede TH, Strange N, Boman M (2018) Disentangling distance and country effects on the value of conservation across national borders. Ecol Econ 147:11-20

Barrett TM, Gray AN (2011) Potential of a national monitoring program for forests to assess change in high-latitude ecosystems. Biol Conserv 144(5):1285-1294

Bosela M, Redmond J, Kučera M, Marin G, Adolt R, Gschwantner T, Petráš R, Korhonen K, Kuliešis A, Kulbokas G, Fischer C, Lanz A (2016) Stem quality assessment in European National Forest Inventories: an opportunity for harmonised reporting? Ann For Sci 73(3):635-648

Cantarello E, Newton AC (2008) Identifying cost-effective indicators to assess the conservation status of forested habitats in Natura 2000 sites. For Ecol Managet 256(4):815-826

Chirici G, Mcroberts RE, Winter S, Bertini R, Brändli U, Alberdi I, Bastrup-Birk A, Rondeux J, Barsoum N, Marchetti M (2012) National Forest Inventory contributions to forest biodiversity monitoring. For Sci 58(3):257-268

Corona P, Chirici G, McRoberts RE, Winter S, Barbati A (2011) Contribution of large-scale forest inventories to biodiversity assessment and monitoring. For Ecol Manag 262:2061-2069

COST Action E43 (2010) Harmonisation of National Forest Inventories in Europe: techniques for common reporting. http://www.cost.eu/ COST_Actions/fps/E43 . Accessed 23 Jan 2018

COST Action Usewood (2014) Improving data and information on the potential supply of wood resources - a European approach from multisource National Forest Inventories. http://www.cost.eu/ COST Actions/fps/usewood? . Accessed 23 Jan 2018

Duarte I, Rego FC, Casquilho J, Arsénio P (2016) A relevance index for the habitat areas of Natura 2000 network based on their rarity and representativeness. Ecol Indic 61:202-213

EC (1991) CORINE biotopes manual. Data specifications - Volume 3. Luxembourg: Office for Official Publications of the European Communities. ISBN 92-826-3210-5

EC (2013a) European Commission 2013. Interpretation manual of European Union habitats - EUR 28 DG Environment - Nature and Biodiversity http://ec.europa.eu/environment/nature/legislation/ habitatsdirective/docs/Int_Manual_EU28.pdf. Accessed 20 Jan 2018

EC (2013b) European Commission, COM 2013. 659 final. A new EU forest strategy: for forests and the forest-based sector. https://ec. europa.eu/agriculture/forest/strategy_es. Accessed 13 Jan 2018

EC (2015a) European Commission. Brussels, COM(2015) 219 final. Report from the Commission to the Council and the European Parliament. The State of Nature in the European Union. Report on the status of and trends for habitat types and species covered by the Birds and Habitats Directives for the 2007-2012 period as required under Article 17 of the Habitats Directive and Article 12 of the Birds Directive

EC (2015b) European Commission. Natura 2000 and Forests Part I-II. Technical report 2015, 88. European Commission, DG Environment

Ellmauer T (2005) Entwicklung von kriterien, indikatoren und schwellenwerten zur beurteilung des erhaltungszustandes der Natura 2000-schutzgu" ter. Band 3: Lebensraumtypen des anhangs I der fauna-flora-habitat-richtlinie. Bundesministerium fur Landund Forstwirtschaft, Vienna

Espinosa S, San Miguel A, Vallejo R, Cañellas I, Alberdi I (2018) Uso del Inventario Forestal Nacional en la evaluación del estado de conservación de los bosques de la Red natura 2000. Montes 132: $22-28$

European Environment Agency (2016) Natura 2000 data - the European network of protected sites. https://www.eea.europa.eu/data-andmaps/data/natura-8. Accessed 11 Jan 2018

Evans D (2010) Interpreting the habitats of Annex I: past, present and future. Acta Bot Gall 157(4):677-686. https://doi.org/10.1080/ 12538078.2010 .10516241
Evans D (2012a) Building the European Union's Natura 2000 network. J Nat Conserv 1:11-26

Evans D (2012b) Interpreting the habitats of Annex I. https://biodiversity. eionet.europa.eu/.../Habitat_manuals.pdf. Accessed 20 Jan 2018

Evans D, Arvela M (2011) Assessment and reporting under Article 17 of the Habitats Directive. Explanatory Notes \& Guidelines for the period 2007-2012. European Commission, Brussels

Gleason HA (1922) On the relation between species and area. Ecology $3(2): 158-162$

Gschwantner T, Schadauer K, Vidal C, Lanz A, Tomppo E, Di Cosmo L, Robert N, Englert Duursma D, Lawrence M (2009) Common tree definitions for National Forest Inventories in Europe. Silva Fenn 43: 303-321

Haraszthy L (2014) Natura 2000 fajok és élőhelyek Magyarországon. Pro Vértes Közalapítvány, Csákvár, 934 p. (FHT - 13 habitat types, page 866-926. http://www.novenyzetiterkep.hu/sites/ novenyzetiterkep.hu/files/natura-2000-fajok-es-elohelyekmagy arorszagon-EL OHELYEK-L.pdf ; http:// termeszetvedelmikezeles.hu/elohelyek?cat $1=4 \&$ cat $2=16 \&$ cat $3=$ 102 . Accessed 20 Jan 2018

Hegetschweiler KT, Plum C, Fischer C, Brändli UB, Ginzler C, Hunziker M (2017) Towards a comprehensive social and natural scientific forest-recreation monitoring instrument - a prototypical approach. Landsc Urban Plan 167:84-97

IPBES (2012) Report of the second session of the plenary meeting to determine modalities and institutional arrangements for an intergovernmental science-policy platform on biodiversity and ecosystem services, Appendix 1, para 2d. UNEP/IPBES.MI2/9. Bonn, Germany

Jensen FS, Skov-Petersen H, Johannsen VK (2008) Friluftslivstatistik: Strategiog manual 2008. Skov \& Landskab, Frederiksberg, $165 \mathrm{p}$

JNCC (2004) Common standard monitoring guidance for woodland habitats, Version February. Joint Nature Conservation Committee, Peterborough, ISSN: 1743-8160

Kovac M, Bauer A, Ståhl G (2014) Merging national forest and national forest health inventories to obtain an integrated forest resource inventory -experiences from Bavaria, Slovenia and Sweden. PLoS One 9:e100157. https://doi.org/10.1371/journal.pone.0100157

Kovac M, Kutnar L, Hladnik D (2016) Assessing biodiversity and conservation status of the Natura 2000 forest habitat types: tools for designated forestlands stewardship. For Ecol Manag 359:256-267

Kovac M, Hladnik D, Kutnar L (2017) Biodiversity in (the Natura 2000) forest habitats is not static: its conservation calls for an active management approach. J Nat Conserv. https://doi.org/10.1016/j.jnc. 2017.07.004

Larsson T-B, Angelstam P, Balent G, Barbati A, Bijlsma R-J, Boncina A, Bradshaw R, Bucking W, Ciancio O, Corona P, Diaci J, Dias S, Ellenberg H, Fernendes FM, Fernández-Gonzaleg F, Ferris R, Frank G, Møller PF, Giller PS, Gustafsson L, Halbritter K, Hall S, Hansson L, Innes J, Jactel H, Keannel Dobbertin M, Klein M, Marchetti M, Moheren F, Niemela P, O'Halloran J, Rametsteiner E, Rego F, Scheidegger C, Scotti R, Sjoberg K, Spanos I, Spanos C, Standovár T, Svensson L, Tømmeras A, Trakolis D, Uttera J, Walsh PM, Vandekerkhove K, Watt AD, VanDenMeersschaut D (2001) Biodiversity evalution tools for European forests. In: Ecological Bulletins No. 50. Wallin\&Dalholm, Lund, Sweden

MARM (2009) Ministerio de Medio Ambiente y Medio Rural y Marino. Bases ecológicas preliminares para la conservación de los tipos de Hábitat de Interés Comunitario en España. Madrid. http://www. mapama.gob.es/es/biodiversidad/temas/espacios-protegidos/rednatura-2000/rn_tip_hab_esp_bases_eco_preliminares.aspx Accessed 12 Jan 2018

McRoberts RE, Winter S, Chirici G, LaPoint E (2012) Assessing forest naturalness. For Sci 58(3):294-309 
MEA (2005) Millennium Ecosystem Assessment. Ecosystems and human well-being: wetlands and water. World resources institute, Washington, DC 5

Müller J, Bütler R (2010) A review of habitat thresholds for dead wood: a baseline for management recommendations in European forests. Eur J For Res 129:981-992

OJEC. (1979). Council Directive 79/409/EC of 2 April 1979 on the conservation of the wild birds. http://eur-lex.europa.eu/legal-content/ EN/TXT/?uri=CELEX:32009L0147/ Accessed 12 Jan 2018

OJEC (1992) Council Directive 92/43/EEC of 21 May 1992 on the conservation of natural habitats and of wild fauna and flora. http://ec. europa.eu/environment/nature/legislation/habitatsdirective/index en.htm/ Accessed 12 Jan 2018.

Orlikowska EH, Roberge JM, Blicharska M, Mikusiński G (2016) Gaps in ecological research on the world's largest internationally coordinated network of protected areas: a review of Natura 2000. Biol Conserv 200:216-227

Preston FW (1948) The commonness, and rarity, of species. Ecology 29(3):254-283

Ramão C (2015) State of nature in the EU. Results from reporting under the nature directives 2007-2012. European Environment Agency. Technical report, (2)

Rodwell J, Dring J, Pignatti S, Schaminée J, Mucina L (1998) Scientific background to the EUNIS habitat classification. Lancaster University, Lancaster

Rondeux J, Bertini R, Bastrup-Birk A, Corona P, Latte N, McRoberts RE, Chirici G (2012) Assessing deadwood using harmonized national forest inventory data. For Sci 58(3):269-283

San-Miguel-Ayanz J, de Rigo D, Caudullo G, Houston TD, Mauri D (eds) (2016) European atlas of forest tree species. European Commission, Brussels

Sievänen T (Ed.) (2013) Social indicators in the forest sector in northern Europe: a review focusing on nature-based recreation and tourism. Nordic Council of Ministers

SOEF (2015) Europe, F., \& Unece, F. A. O. State of Europe's forests 2015. Europe's status \& trends in sustainable forest management in
Europe. In: Project coordinator: Martin M, Forest Europe. Liaison Unit Madrid, Madrid

Tomppo E, Schadauer K, McRoberts RE, Gschwantner T, Gabler K, Ståhl G (2010) Introduction. In: Tomppo E, Gschwantner T, Lawrence M, McRoberts RE (eds) National Forest Inventories: pathways for common reporting. Springer, Berlin, pp 597-609

Tomter SM, Gasparini P, Gschwantner T, Hennig P, Kulbokas G, Kuliešis A, Polley H, Nicolas R, Rondeux J, Tabacchi G, Tomppo E (2012) Establishing bridging functions for harmonising growing stock estimates - examples from European National Forest Inventories. For Sci 58:224-235

UN Rio Conference (1992). http://www.un.org/documents/ga/conf151/ aconf15126-1annex1.htm. Accessed 12 Jan 2018

Velázquez J, Tejera R, Hernando A, Núñez MV (2010) Environmental diagnosis: integrating biodiversity conservation in management of Natura 2000 forest spaces. J Nat Conserv 18:309-317

Vidal C, Lanz A, Tomppo E, Schadauer K, Gschwantner T, Di Cosmo L, Robert N (2008) Establishing forest inventory reference definitions for forest and growing stock: a study towards common reporting. Silva Fenn 42(2):247-266

Vidal C, Alberdi I, Hernández L, Redmond J (eds) (2016) National Forest Inventories: assessment of wood availability and use. Springer, Berlin

Winkel G, Blondet M, Borrass L, Frei T, Geitzenauer M, Gruppe A, Jump A, Koning J, Sotirov M, Weiss G, Winter S, Turnhoutg E (2015) The implementation of Natura 2000 in forests: a trans- and interdisciplinary assessment of challenges and choices. Environ Sci Pol 52:23-32

Winter S, Chirici G, McRoberts RE, Hauk E, Tomppo E (2008) Possibilities for harmonizing national forest inventory data for use in forest biodiversity assessments. Forestry 81(1):33-44

Wurzel R K (2008) European Union environmental policy and Natura 2000. Legitimacy in European nature conservation policy: case studies in multilevel governance, pp 259-282

Publisher's note Springer Nature remains neutral with regard to jurisdictional claims in published maps and institutional affiliations.

\section{Affiliations}

\section{Iciar Alberdi ${ }^{1}$ (D) - Leónia Nunes ${ }^{2,3} \cdot$ Marko Kovac $^{4} \cdot$ Ingrid Bonheme ${ }^{5} \cdot$ Isabel Cañellas $^{1} \cdot$ Francisco Castro Rego $^{2}$. Susana Dias ${ }^{2} \cdot$ Inês Duarte ${ }^{2} \cdot$ Monica Notarangelo $^{6} \cdot$ Maria Rizzo $^{6}$. Patrizia Gasparini ${ }^{6}$}

1 Instituto Nacional de Investigación y Tecnología Agraria y Alimentaria (INIA-CIFOR). Dpto. Selvicultura y Gestión de los Sistemas Forestales, Ctra. La Coruña km. 7.5, 28040 Madrid, Spain

2 Centre for Applied Ecology "Professor Baeta Neves" (CEABN), InBIO, School of Agriculture, University of Lisbon, Tapada da Ajuda, 1349-017 Lisbon, Portugal

3 Centre of the Research and Technology of Agro-Environmental and Biological Science (CITAB), University of Trás-os-Montes and Alto Douro, Qta. de Prados, 5000-801 Vila Real, Portugal
4 Slovenian Forestry Institute (SFI), Večna pot 2, 1000 Ljubljana, Slovenia

5 Institut National de l'Information Géographique et Forestière (IGN), Forest Inventory Laboratory, 14 rue Girardet, 54042 Nancy, France

6 CREA-MPF, Unità di ricerca per il Monitoraggio e la Pianificazione Forestale, Consiglio per la Ricerca in Agricoltura e l'Analisi dell'Economia Agraria, p.zza Nicolini 6, 38123 Trento, Italy 